\title{
Visuospatial Ability As A Predictor Of Novice Performance In Ultrasound - Guided Regional Anesthesia
}

Authors:

Atif Shafqat M.B.B.S., D.A., M.Sc., M.R.C.A., Ph.D. Anesthesiology Fellow, University Dept. of Anesthesia \& Intensive Care, Queen's Medical Centre, University of Nottingham, UK, NG7 2UH

Eamonn Ferguson B.Sc., Ph.D., CPsychol., AFBPsS., FRSH, Professor of Health Psychology, School of Psychology, University of Nottingham, UK, NG7 2RD

Vishal Thanawala M.B.B.S., M.D., E.D.R.A., F.R.C.A., Consultant Anesthesiologist, University Dept. of Anesthesia \& Intensive Care, Queen's Medical Centre, Nottingham University Hospitals NHS Trust, Nottingham, UK, NG7 2UH

Nigel M Bedforth B.Med.Sci., B.M., B.S., F.R.C.A., Consultant Anesthesiologist \& Honorary Associate Professor, University Dept. of Anesthesia \& Intensive Care, Queen's Medical Centre, Nottingham University Hospitals NHS Trust, Nottingham, UK NG7 2UH

Jonathan G Hardman B.Med.Sci., B.M., B.S., F.A.N.Z.C.A., F.R.C.A., D.M., Professor Anesthesia and Critical Care, University of Nottingham, Honorary Consultant Anesthesiologist, University Dept. of Anesthesia \& Intensive Care, Queen's Medical Centre, Nottingham University Hospitals NHS Trust, Nottingham, UK, NG7 2UH.

Robert A McCahon M.B., Ch.B., F.R.C.A., M.Med.Sci., Consultant Anesthesiologist \& Honorary Associate Professor, University Dept. of Anesthesia \& Intensive Care, Queen's Medical Centre, Nottingham University Hospitals NHS Trust, Nottingham, UK, NG7 2UH 


\section{Corresponding Author:}

Atif Shafqat

University Dept. of Anesthesia \& Intensive care

Queen's Medical Centre, Nottingham University Hospitals NHS Trust

Nottingham, UK, NG7 2UH

Email: shafqatatif@hotmail.com

Tel: $\quad+44(0) 7595306906$

Disclosure Of Funding: $\quad$ This study was supported by an educational grant from Regional Anesthesia - United Kingdom (RA-UK), 21 Portland Place, London, U.K. for research project "Visuospatial ability as a predictor of novice performance in ultrasound-guided regional anesthesia (USGRA)".

Individuals Or Organizations To Be Acknowledged: None

Number Of Words In Abstract, In Introduction, And In Discussion:

Abstract - 248; Introduction - 372 Discussion - 954

An Abbreviated Title: Visuospatial ability as a predictor of USGRA skill

Brief Summary Statement: $\quad$ Not required 


\section{Conflicts of Interest:}

\section{Professor Jonathan G Hardman:}

He is an editor of British Journal of Anesthesia.

\section{Eamonn Ferguson:}

He was a principle-investigator on a case award grant from the ESRC (Integrating Prospect theory (Framing Effects) and the Common Sense Model of illness to improve medication compliance in glaucoma patients), He was a co-investigator on a grant from Chief Scientists Office - Scotland (A randomized controlled trial to test if a simple anticipated regret manipulation leads to a significant increase in organ donor registrations), $\mathrm{He}$ is a joint $\mathrm{PhD}$ supervisor on a project with Experian (Potential of Psychological Information to inform credit scoring), He is a co-investigator on a grant from DEFRA (Overcoming barriers to uptake of best welfare practice by sheep farmers), He is a coinvestigator on a grant from Pfizer (Pain phenotypes in rheumatoid arthritis: a patient-centered, stratified approach to optimizing disease modifying and analgesic treatments, $\mathrm{He}$ is a co-investigator on a grant from Arthritis UK Research (Pain Centre), He supervise externally funded PhD students ESRC PhD studentships (reluctant altruism, Schizophrenia and Empathy). He was paid as an Associate Editor for Journal of Behavioral Medicine and as Deputy Editor British Journal of Psychology. He is paid as an Associate Editor for Annals of Behavioral Medicine. He is an invited speaker at ISBT (expenses and travel paid), He is paid as an External Examiner at Edinburgh University and Lancaster University. He have had expenses paid to presents talk at (1) Workshop: Right Patient, Right Place, Right Time: When And How To Use The Emergency Department: Health Literacy, Decision-Making And Communication. Unversita Cattolic del Sacro Cuore. Milan, Italy, April 11th-12th, (2) Taxometrics, Psychometrics and Clinometrics: Stratified Medicine and Assessing Phenotypes. Economic and Social Research Council (ESRC) Advanced Quantitative Methods 
National Conference, White Rose DTC, Sheffield University, Sheffield, 24th to 25th July 2014, (3) Personality: Myths, Misconceptions and Misunderstandings - Implications for Current and Future Medical Education, Selection and Training. INReSH London, 10-11th November. He receive royalties each year from GL Assessment for the Pediatric Index of Emotional Distress (PI-ED). He is coinvestigator on a grant from the US Defense Medical Research and Development Program (Study to examine psychological processes in suicidal ideation and behavior). This does not relate directly to the current submitted work but is a different grant. He is a co-investigator on a grant from the ESRC (Individual Differences in the Impact of Socio- Economic Events on Health and Well-being). This does not relate directly to the current submitted work but is a different grant.

Nigel M. Bedforth:

Run \& a faculty member on teaching courses sponsored by Sonosite Ltd. NIHR National Institute for Health Research - Research for the Patient Benefit.

"All other authors have no conflicts of interest." 


\section{ABSTRACT:}

Background: Visuospatial ability correlates positively with novice performance of simple laparoscopic tasks. The aims of this study were to identify if visuospatial ability could predict technical performance of an ultrasound-guided needle task by novice operators, and to describe how emotional state, intelligence and fear of failure impact on this.

Methods: Sixty medical student volunteers enrolled in this observational study. We used an instructional video to standardize training for ultrasound-guided needle advancement in a turkey breast model and assessed volunteers' performance independently by two assessors using composite error score (CES) and global rating scale (GRS). We assessed their 'visuospatial ability' with mental rotation test (MRT), group embedded figures test (GEFT) and Alice Heim group ability (AH4) test. 'Emotional state' was judged with UWIST mood adjective checklist (UMACL) and fear of failure, and 'general cognitive ability' with numerical reasoning test (NRT-20).

Results: High CES scores (high error rate) were associated with low MRT scores $(\rho=-0.54$; $\mathrm{P}<0.001)$. Better GRS scores were associated with better MRT scores $(\rho=0.47 ; \mathrm{P}<0.001)$. Regarding emotions, GRS scores were low when anxiety levels were high $(\rho=-0.35 ; \mathrm{P}=$ 0.005) and CES scores (errors) were low when individuals reported feeling vigorous and active $(\rho=-0.30 ; P=0.01)$.

Conclusions: MRT predicts novice performance of an ultrasound-guided needling task on a turkey model, and as a trait measure could be used as a tool to focus training resources on less able individuals. Anxiety adversely affects performance. Both may therefore prove useful in directing targeted training in USGRA. 


\section{INTRODUCTION:}

The ability to perform practical procedures competently is essential to the safe practice of anesthesia. Ultrasound-guided regional anesthesia (USGRA) is a complex, invasive procedural skill that requires manual dexterity, hand-eye coordination and a working knowledge of sono-anatomy. ${ }^{1}$ International regional anesthesia societies have emphasized the need for training and competency assessment in USGRA to ensure safe practice. ${ }^{2-4}$ However, some trainees will learn more quickly than others. ${ }^{5}$ Early identification of those who may require additional support is key to developing efficient expertise acquisition within the time constraints of postgraduate training.

Mental rotation is a visuospatial ability to mentally rotate and manipulate 2-D and 3-D objects. Mental rotation correlates positively with novice performance of simple laparoscopic tasks on bench-top models. ${ }^{6-9}$ At a basic level, it is possible that laparoscopy and USGRA are similar with respect to the interaction of the operator's hands and eyes with the ultrasound probe/laparoscope, the patient and the screen. The importance of visuospatial ability has been emphasized in USGRA skills acquisition. ${ }^{1}$ However, there is little evidence to support the use of visuospatial testing to identify individuals who may benefit from early, targeted training in USGRA. The primary aim of this study was to determine whether visuospatial ability could predict technical performance of an ultrasound-guided needle task by novice operators. Specifically, we chose to study the Mental Rotation Test (MRT), the Group Embedded Figures Test (GEFT), and the Alice Heim Group Ability Test (AH4).

Previous studies have considered the impact of visuospatial ability on novice skill performance in isolation. However, the role of traits and state emotional processes are also 
important for a fuller understanding of healthcare provision through their influence on clinical skills acquisition. ${ }^{10,11}$ Specifically, previous studies have not investigated the interplay between skill performance and emotional processing. ${ }^{1,12-14}$ Two emotional components are relevant here. State anxiety is well known to be related to performance. ${ }^{15}$ The trait, fear of failure, is a sub-clinical form of state anxiety when success is being valued. ${ }^{16,17}$ Fear of failure could potentially hinder performance. ${ }^{18,19}$ In addition, general cognitive ability is considered to be one of the best predictors of performance overall. ${ }^{20}$ Therefore, we also aimed to study the relationship between emotional state, fear of failure and intelligence with novice skill performance of an ultrasound-guided needle task. 


\section{MATERIALS AND METHODS:}

The study was reviewed and approved by the University of Nottingham Medical School Research Ethics Committee (Approval Reference; L13092012 SCS Anesthesia). Medical students from the University of Nottingham Medical School were invited to participate in the study through poster advertising. Students who expressed a wish to participate were emailed a participant information leaflet and an invitation to attend the study. Written informed consent for the study, including video recording, was taken from all participants.

Design: This single center, prospective, blinded observational study was conducted at the University Department of Anesthesia, Queen's Medical Centre, Nottingham University Hospitals NHS Trust, Nottingham UK.

Subjects with previous experience of ultrasound scanning or of performing regional anesthesia were excluded from the study. The study was organized in four phases [figure 1]. The enrolled medical students were asked to undergo and complete all four phases of the study. Participants' identities were masked throughout the study, and their assessments were concealed from view within individual folders. Assessors of the ultrasound-guided needling task (phase four) were blinded to the outcomes of the preceding assessments.

\section{PHASE ONE:}

We collected basic demographic data including age, sex, year of study in medical school and previous experience of USGRA. 


\section{PHASE TWO:}

This phase consisted of standardized visuospatial, emotional, and numerical reasoning assessments of the study participants. The assessments were paper-based and administered under examination conditions, as per their standardization. Participants were blinded to the study hypothesis and their test scores. Brief descriptions of each visuospatial, emotional, and numerical reasoning assessment are described in the next paragraphs.

\section{Visuospatial Assessments:}

The visuospatial assessments consisted of the Mental Rotation Test (MRT), Group Embedded Figures Test (GEFT) and Alice Heim Group Ability Test (AH4).

\section{${\underline{\text { Mental rotation Test }(M R T)^{21-23}}}^{2}$}

There are four different variations of MRT, which include MRT-A, MRT-B, MRT-C and MRT-D respectively. We used MRT-A, which consists of 24 problem figures. Each problem task has a target figure on the left and four stimulus figures on the right. Two of these stimulus figures are rotated versions of the target figure and two of the stimulus figures cannot be matched to the target figure. The aim is to mentally rotate the figures around the vertical axis to find the two correct rotated versions of the target figure. Participants were given four minutes to complete the first set of 12 problem tasks, followed by a one-minute break before completing the second set of 12 problem tasks in the next four minutes. 


\section{The Group Embedded Figures Test $(\text { GEFT })^{24,25}$}

The GEFT measures field-independence, which is the ability to perform a focal task independently of any background information or distracters. The aim is to find a previously seen simple figure within a larger complex figure, which has been structured in a way to obscure or embed the simple figure. The participants were required to identify and outline accurately a simple shape embedded in a complex figure. The test consists of three sections. The participants were initially given two minutes to complete the seven problems in the first section. Following this, second and third sections consisting of nine problems each respectively were completed in 10 minutes.

\section{Alice Heim Group Ability Test $(\mathrm{AH} 4)^{26}$}

The AH4 is designed as a group test of general intelligence, which primarily assesses deductive reasoning including verbal, mathematical and spatial reasoning. We used AH4 to assess spatial reasoning skills, which is the ability to visualize, mentally rotate and manipulate two-dimensional or three-dimensional shapes or patterns. The test consists of 65 questions and participants were given 10 minutes to complete as many questions as possible.

\section{Emotional Assessments:}

Emotional processes that tap into state anxiety or tense arousal, as well as positive mood states (e.g., energetic arousal), were assessed using the UWIST Mood Adjective Checklist (UMACL) and Fear of Failure. 


\section{$\underline{\text { UWIST Mood Adjective Checklist (UMACL) }}^{27}$}

The UMACL is used to measure mood and comprises three bipolar scales: energetic arousal (EA) [vigorous vs. tired: coefficient alpha $=.79$ ], tense arousal (TA) [nervous vs. relaxed: coefficient alpha $=.76$ ] and hedonic tone $(\mathrm{HT})$ [pleasant vs. unpleasant mood: coefficient alpha $=.81] .{ }^{28}$ In addition to these scales, a mono-polar anger/frustration (AF: coefficient alpha $=.80)$ scale was also used. The participants were instructed to complete the UMACL checklist according to their present mood using 28 adjectives each on a four - point scale ('definitely', 'slightly', 'slightly not' or 'definitely not').

\section{Fear of Failure ${ }^{29}$}

'Fear of failure' assesses the general preference to be motivated not to succeed but to avoid failing. This assessment consists of four statements pertaining to fear of failure, each scored on a four - point scale ('always', 'often', 'rarely' and 'never'). Scores were then obtained by summating the item scores. The reported coefficient alpha was .70 .

\section{Numerical Reasoning Assessments:}

\section{Numerical Reasoning Test (NRT-20)}

This test measures mathematical and logical reasoning via 20 short reasoning problems based on numbers that do not require any previous training in mathematics. It is a test of fluid intelligence, which depicts skills of problem solving, abstract reasoning, and ability to learn new things, irrespective of prior knowledge or education. There are 20 items,

\footnotetext{
${ }^{*}$ Chamorro-Premuzic T: The Numerical Reasoning Test 20-Items (NRT-20). Goldsmiths: University of London, 2008. (Unpublished Test)
} 
which include series completion (numbers and matrices), basic arithmetic problems (computational speed), and other deductive reasoning tasks. The participants were given 15 minutes to solve as many problems as possible.

\section{PHASE THREE:}

In this phase the participants were given 30 minutes to watch and review an 11 - minute video $^{30}$ mapped to specific learning objectives, which modeled expert performance of ultrasound-guided needle advancement in a turkey breast model.

The learning objectives were:

I. Switch on the ultrasound machine (S-Series, Sonosite Limited, Hitchen, UK).

II. Correctly orientate the ultrasound probe (linear, $38 \mathrm{~mm}$ ) in relation to the display on the screen.

III. Ensure adequate application of conducting gel to enhance ultrasound transmission and picture quality.

IV. Locate and identify the target (olive) within the turkey breast.

V. Adjust the gain function to improve the quality of the image by altering brightness of the picture.

VI. Alter the depth of the image to obtain a suitable image of the target.

VII. Using an in-plane approach, insert a $50 \mathrm{~mm}$ Stimuplex ${ }^{\circledR}$ A needle (B. Braun, Melsungen, Germany) into the turkey breast and aim to place the needle tip at the 12 
o'clock position, as indicated by the attending assessors, above the upper edge of the target, without piercing the target.

\section{PHASE FOUR:}

The fourth phase included an ultrasound-guided needling task and its assessment. Participants were asked to complete the ultrasound-guided needling task, as demonstrated in the video, on a turkey breast model $^{31,32}$ using a standard ultrasound transducer probe (38-mm highfrequency linear array transducer; HFL38X 13-6 MHz, Sonosite Limited, Hitchen, UK). In order to improve realism, the turkey breast model was inserted into the draped groin recess of a Laerdal $^{\circledR}$ IV Torso manikin (Laerdal Medical Limited, Orpington, Kent, UK), which was used solely for this study. The participants received no help or feedback before or during the task. Study participation ceased once the ultrasound-guided needling task was completed.

Participants were independently assessed by two anesthesiologists experienced in USGRA as they performed the task. The assessors used two previously validated assessments of USGRA technical performance; composite error score (CES) ${ }^{32-34}$ [appendix 1] and global rating scale $(G R S)^{35-37}$ [appendix 2]. The assessors had undergone specific training and practice in the use of these assessment tools. The CES was calculated by adding the total number of errors, number of needle passes and image quality score for each participant. A lower composite error score is associated with better accuracy and task performance. The GRS consisted of seven items each rated on a five - point scale. The GRS predominantly assessed more general behaviors and the overall performance of the participant. 


\section{Statistical Analysis:}

Descriptive statistics for demographic and outcome measure data were calculated. CES data follow a non-normal distribution, and are thus presented as median (IQR). Normality of other data was assessed by histogram and the Shapiro-Wilk and Skewness / Kurtosis tests.

We performed an initial exploratory analysis using Spearman's correlation coefficient ' $\rho$ ' (rho) to determine which of the six explanatory variables was the most predictive of better task performance. The count data (CES) were over-dispersed. This was unlikely due to excessive zeros as the proportion of extra zeros was considerably small $(4 / 60=6.66 \%)$; therefore negative-binomial regression analysis was conducted for CES. For continuous data the relationship between each potential explanatory variable and GRS was evaluated in an ordinary least square (OLS) regression. Bonferroni corrections were applied for multiple testing. We then created a regression model using the explanatory variable most predictive of performance. In order to examine which aspects of USGRA technical performance were most strongly correlated with visuospatial ability, we then deconstructed both assessments into their respective domains in order to perform a sub-analysis with the predictive variable; this sub-analysis was outside the previous validation of the CES and GRS. To achieve a study power of $0.8(\alpha=0.05)$, we calculated that we would need to recruit 60 participants for this model with an assumed moderate effect $\operatorname{size}^{38}(r=0.3-0.5)$.

We chose to make non-pairwise comparisons between males and females in order to determine whether any differences in visuospatial ability existed. In all cases, we used P values less than 0.05 (two-tailed) to indicate statistical significance. 
Reliability of the assessment tools i.e. CES and GRS, was evaluated using Intra-class correlation coefficient (ICC), Cronbach's alpha coefficient and standard error of the measurement as a percentage of the mean (SEM [\%]). ${ }^{39,40}$ The statistical analysis software STATA/IC version 10.0 (StataCorp, Texas, USA) was used for data analysis. 


\section{RESULTS:}

All individuals who expressed an interest in participating in the study were recruited. Participant demographics and summary statistics for visuospatial ability and task performance are summarized in table 1. Males were found to exhibit better mental rotation skills compared to females $(\mathrm{P}<0.001)$ [table 2].

\section{Reliability of CES and GRS:}

The intra-class correlation coefficient and SEM (\%) for CES and GRS was $0.97(15.29 \%)$ and $0.91(8.53 \%)$ respectively; this demonstrates a high degree of inter-rater agreement. Similarly, Cronbach's alpha coefficient and SEM (\%) for CES and GRS was 0.98 (9.49 \%) and $0.96(5.69 \%)$ respectively; this demonstrates a high degree of inter-item consistency.

\section{Composite error score (CES) versus Visuospatial ability assessments:}

Of the three visuospatial assessments (MRT, GEFT, AH4), only MRT correlated significantly with CES $(\rho=-0.54 ; \mathrm{P}<0.001)$ [figure 2 , table 3], indicating that a high error rate is associated with low MRT scores. The negative binomial regression coefficients for each variable showed that for each unit increase in MRT, the expected log count of the CES decreases by 0.08 -unit $(\mathrm{P}<0.001)$.

After Bonferroni adjustments ( $\mathrm{P}<0.0016)$, only 'needle advancement without visualization of needle tip' $(\rho=-0.52 ; \mathrm{P}<0.001)$ and 'number of needle passes' $(\rho=-0.45 ; \mathrm{P}<0.001)$ correlated significantly with MRT. 


\section{Global rating scale (GRS) versus Visuospatial ability assessments:}

Of the three visuospatial assessments (MRT, GEFT, AH4), only MRT correlated significantly with GRS $(\rho=0.47 ; \mathrm{P}<0.001)$ [figure 3, table 3], indicating that better performance was associated with better mental rotation skills. An ordinary least square regression established the univariate association of GRS with MRT showing that for a one-unit increase in MRT we would expect a 0.43 -unit increase in GRS $(\mathrm{P}=0.002)$.

After Bonferroni adjustments $(\mathrm{P}<0.0031)$, only 'time and motion' $(\rho=0.44$; $\mathrm{P}<0.001)$, 'instrument handling' $(\rho=0.47 ; \mathrm{P}<0.001)$ and 'flow of procedure' $(\rho=0.44 ; \mathrm{P}<0.001)$ correlated significantly with MRT.

\section{Composite error score (CES) versus Emotional assessments:}

Of the UMACL, energetic arousal (EA) was found to correlate negatively with CES ( $\rho=-$ $0.30 ; \mathrm{P}=0.01$ ) [table 3]. By contrast, tense arousal (TA) correlated positively but weakly with CES ( $\rho=0.26 ; P=0.04)$ [table 3]. This showed that errors would be low in vigorous, active individuals and high in anxious individuals.

The negative binomial regression coefficients for each of the variable showed that for each unit increase on EA, the expected log count of the CES decreases by 0.07 -unit $(P=0.02)$.

\section{Global rating scale (GRS) versus Emotional assessments:}

Of the UMACL, only tense arousal (TA) correlated negatively with GRS $(\rho=-0.35 ; \mathrm{P}=$ 0.005) [table 3]. This showed that GRS quality scores would be low when anxiety level is high. 
An ordinary least square regression established the univariate association of GRS with TA showing that for a one-unit increase in TA we would expect a 0.54 -unit decrease in GRS $(\mathrm{P}=$ $0.01)$. 


\section{DISCUSSION:}

The results indicate that MRT predicts technical performance of an ultrasound-guided needle advancement task by novice operators. The study shows that males are likely to have better mental rotation capabilities than females. This is in line with two previous meta-analyses ${ }^{41,23}$ which showed effect sizes around 0.95 favoring males. This difference means that the MRT cannot be used as a selection tool for medical posts, i.e. high stakes assessment, as men are likely to be preferentially selected and this would introduce indirect sexual discrimination against women. However, that is not to say that males with better MRT scores perform better at the task. Two previous studies of laparoscopic skills have demonstrated that gender does not affect psychomotor performance ${ }^{42,43}$, though the affect of MRT scores of both males and females remained unknown. In an observational study of surgical trainees with very limited laparoscopic experience, Grantcharov ${ }^{43}$ demonstrated that male trainee surgeons made a similar number of errors and unnecessary hand movements as females during their performance of six simulated laparoscopic tasks.

One may suggest that it would be useful to provide a range of MRT scores wherein learners could benefit the most from focused training. However, we are unable to do so at this stage of our work. While our study shows that MRT has a predictive validity for performance of an ultrasound-guided needle task, it does not indicate at what point MRT performance can be defined as adequate or not. Despite this limitation, we believe that it is reasonable to state that low error rates, better image quality, and better global performance are associated with higher MRT scores. Therefore, strategies that aim to develop mental rotation skills could be developed and used to improve ultrasound-guided needle advancement skills. 
We also found that negative mood adversely affects performance. Good performance, therefore, appears to be a function of visuospatial ability and reducing anxiety. Thus, a second practical implication of our study is that stress and anxiety when performing the task may need to be reduced in the training and learning environment. However, in the real clinical setting some level of anxiety will be associated with any clinical intervention, and thus the degree of stress elicited by the task may itself increase its validity. ${ }^{10}$ It may be more relevant for educators to develop curricula that allow novice practitioners to learn the necessary coping skills to deal with the emotional costs of this type of work and procedure.

Limitations are integral to any investigation and warrant specific comment here. Aside from the ethical problems of allowing novice practitioners to practice on real patients, it is likely that anatomical differences, doctor-patient interactions and the pressures of achieving successful blocks would generate inconsistent results in real clinical situations. ${ }^{1,33}$ For the purpose of this study, we used a turkey-breast bench model rather than in-vivo needling. Despite the lack of clinical context, we believe that our participants experienced an "examination-like" stress caused by their assessments during the study. In addition, "live assessment" of the participants may have added to their stress levels. It is likely that the combined stress and fear could produce detrimental and variable effects on performance such as that in clinical practice. ${ }^{15,44,45}$ Despite the limitations of the turkey-breast bench model, it is accepted as an initial means to evaluate novice performance in USGRA $^{3}$ and to perform training in this complex technical task. ${ }^{31}$ As such, we felt that our bench-top simulation provided a reproducible and realistic environment in which to assess our subjects.

The subjects were medical students and not practicing doctors, therefore one could argue that with seniority and experience there is an inherent level of psychomotor expertise, which 
confers an improved ability to perform new psychomotor skills. Thus, it could be debated that had we studied anesthesiology residents, the correlations between MRT and GRS or CES may have been weaker. However, previous work has demonstrated that medical student performance of an ultrasound-guided needle task is broadly comparable to that of novice resident doctors. ${ }^{32,33}$ Hence, we do not consider that the use of medical student volunteers presents a significant limitation to our study; rather the fact that they have no experience may be considered a positive aspect of the study.

We have used assessments of visuospatial ability, emotional processing and general cognitive ability, which are considered to be valid and reliable. ${ }^{21-27}$ With regard to CES and GRS, we have demonstrated high levels of inter-rater agreement and internal consistency of the assessment tools; this is in line with the previous findings. ${ }^{33,37}$ We believe that the high interrater agreement reflects the assessor training with the CES and GRS tools, prior to recruitment. As such, we believe that our measurement of task performance is both reliable and valid.

Lastly, we have attempted to mitigate for any bias in assessment by asking our assessors to rate the participants' performance independent of one another, and without knowledge of the participants' scores in the various psychological assessments completed beforehand.

The premise of this study was to identify whether visuospatial ability could be used to predict technical performance of an ultrasound-guided needle task by novice operators. In doing so, we have identified correlations between performance, mental rotation skills, and negative mood. As a trait measure, MRT has the potential to be used as a tool to focus educational and training resources on individuals who have less ability to perform ultrasound-guided needle tasks. 
Future research could investigate whether specific training interventions could transform visuospatial ability and thus enhance skills acquisition in USGRA. In broader terms, we believe that the predictive value of MRT in video-laryngoscopy and fibreoptic intubation should be investigated. With regard to MRT as a screening tool to focus training, we believe that future studies need to assess the sensitivity and specificity of MRT in this context. 
References:

1. Smith HM, Kopp SL, Johnson RL, Long TR, Cerhan JH, Hebl JR: Looking into learning: visuospatial and psychomotor predictors of ultrasound-guided procedural performance. Reg Anesth Pain Med 2012; 37: 441-7

2. National Institute of Clinical Excellence: Ultrasound Guided Regional Nerve Block. http://www.nice.org.uk/nicemedia/live/11931/42876/42876.pdf $\quad$ (Accessed 20/12/2013). 2009

3. Association of Anaesthetists of Great Britain and Ireland. Ultrasound in Anaesthesia and Intensive Care: a Guide to Training. London:AAGBI, 2011. http://www.aagbi.org/sites/default/files/Ultrasound\%20in\%20Anaesthesia\%20and\%20Intensi ve\%20Care\%20-\%20A\%20Guide\%20to\%20Training.pdf (accessed 20/12/2013). 2011

4. Sites BD, Chan VW, Neal JM, Weller R, Grau T, Koscielniak-Nielsen ZJ, Ivani G: The American Society of Regional Anesthesia and Pain Medicine and the European Society Of Regional Anaesthesia and Pain Therapy Joint Committee recommendations for education and training in ultrasound-guided regional anesthesia. Reg Anesth Pain Med 2009; 34: $40-6$

5. Dalal PG, Dalal GB, Pott L, Bezinover D, Prozesky J, Bosseau Murray W: Learning curves of novice anesthesiology residents performing simulated fibreoptic upper airway endoscopy. Can J Anaesth 2011; 58: 802-9

6. Westman B, Ritter EM, Kjellin A, Torkvist L, Wredmark T, Fellander-Tsai L, Enochsson L: Visuospatial abilities correlate with performance of senior endoscopy specialist in simulated colonoscopy. J Gastrointest Surg 2006; 10: 593-9

7. Hedman L, Strom P, Andersson P, Kjellin A, Wredmark T, Fellander-Tsai L: High-level visual-spatial ability for novices correlates with performance in a visual-spatial complex surgical simulator task. Surg Endosc 2006; 20: 1275-80

8. Ahlborg L, Hedman L, Murkes D, Westman B, Kjellin A, Fellander-Tsai L, Enochsson L: Visuospatial ability correlates with performance in simulated gynecological laparoscopy. Eur J Obstet Gynecol Reprod Biol 2011; 157: 73-7

9. Wanzel KR, Hamstra SJ, Caminiti MF, Anastakis DJ, Grober ED, Reznick RK: Visual-spatial ability correlates with efficiency of hand motion and successful surgical performance. Surgery 2003; 134: 750-7

10. Ferguson E, Semper H, Yates J, Fitzgerald JE, Skatova A, James D: The 'dark side' and 'bright side' of personality: when too much conscientiousness and too little anxiety are detrimental with respect to the acquisition of medical knowledge and skill. PLoS One 2014; 9(2): e88606 
11. Ferguson E: Personality is of central concern to understand health: towards a theoretical model for health psychology. Health Psychol Rev 2013; 7(Suppl 1): S32-S70

12. Wanzel KR, Hamstra SJ, Anastakis DJ, Matsumoto ED, Cusimano MD: Effect of visual-spatial ability on learning of spatially-complex surgical skills. Lancet 2002; 359: $230-1$

13. Stefanidis D, Korndorffer JR, Jr., Black FW, Dunne JB, Sierra R, Touchard CL, Rice DA, Markert RJ, Kastl PR, Scott DJ: Psychomotor testing predicts rate of skill acquisition for proficiency-based laparoscopic skills training. Surgery 2006; 140: 252-62

14. Hassan I, Gerdes B, Koller M, Dick B, Hellwig D, Rothmund M, Zielke A: Spatial perception predicts laparoscopic skills on virtual reality laparoscopy simulator. Childs Nerv Syst 2007; 23: 685-9

15. Hardy L, Parfitt G: A catastrophe model of anxiety and performance. Br J Psychol 1991; 82 ( Pt 2): 163-78

16. Meijer J: Learning potential and anxious tendency: Test anxiety as a bias factor in educational testing. Anxiety, Stress, \& Coping 2001; 14: 337-362

17. Sarason IG: Stress, anxiety, and cognitive interference: reactions to tests. J Pers Soc Psychol 1984; 46: 929-38

18. Elliot A, Pekrun R: Emotion in the hierarchical model of approach-avoidance achievement motivation. In Schutz, Paul A. (Ed); Pekrun, Reinhard (Ed), (2007). Emotion in education. Educational psychology series., (pp. 57-73). . San Diego, CA, Elsevier Academic Press, xiv, 348 pp., 2007

19. Putwain DW, Symes W: Achievement goals as mediators of the relationship between competence beliefs and test anxiety. Br J Educ Psychol 2012; 82: 207-24

20. Bertua C, Anderson N, Salgado JF: The predictive validity of cognitive ability tests: A UK meta-analysis. Journal of Occupational and Organizational Psychology 2005; 78: 387-409

21. Peters M, Laeng B, Latham K, Jackson M, Zaiyouna R, Richardson C: A redrawn Vandenberg and Kuse mental rotations test: different versions and factors that affect performance. Brain Cogn 1995; 28: 39-58

22. Peters M, Chisholm P, Laeng B: Spatial Ability, Student Gender, and Academic Performance. Journal of Engineering Education 1995; 84: 69-73

23. Voyer D, Voyer S, Bryden MP: Magnitude of sex differences in spatial abilities: a meta-analysis and consideration of critical variables. Psychol Bull 1995; 117: 25070 
24. Witkin HA, Oltman, P. K., Raskin, E., \& Karp, S. (1971). A manual for the embedded figures test. Palo Alto, CA: Consulting Psychologists Press.

25. Witkin HA, Oltman, P. K., Raskin, E., \& Karp, S. (1971). Group embedded figures test manual. Palo Alto, CA: Consulting Psychology Press.

26. Heim AW: AH4 Group Test of General Intelligence Manual. Windsor, United Kingdom., NFER-Nelson Publishing Company Limited, 1970

27. Matthews G, Jones DM, Chamberlain AG: Refining the measurement of mood: The UWIST Mood Adjective Checklist. British Journal of Psychology 1990; 81: 17-42

28. Matthews G, Joyner L, Gilliland K, Campbell SE, Falconer S, Huggins J: Validation of a comprehensive stress state questionnaire: Towards a state big three. Personality psychology in Europe 1999; 7: 335-350

29. Caraway K, Tucker CM, Reinke WM, Hall C: Self-efficacy, goal orientation, and fear of failure as predictors of school engagement in high school students. Psychology in the Schools 2003; 40: 417-427

30. Ultrasound-guided needle advancement for novices. https://www.youtube.com/watch?v=5VaXrqjRlVs (Accessed on 10/08/2014). 2013

31. Beese RC, Lowe S: The use of turkey breast and stuffed olives as a soft tissue model for the teaching and practice of ultrasound guided interventional procedures. European Journal of Ultrasound 1998; 7: 12-12

32. Sites BD, Gallagher JD, Cravero J, Lundberg J, Blike G: The learning curve associated with a simulated ultrasound-guided interventional task by inexperienced anesthesia residents. Reg Anesth Pain Med 2004; 29: 544-8

33. Davies T, Townsley P, Jlala H, Dowling M, Bedforth N, Hardman JG, McCahon RA: Novice performance of ultrasound-guided needle advancement: standard 38$\mathrm{mm}$ transducer vs 25-mm hockey stick transducer. Anaesthesia 2012; 67: 855-61

34. Sites BD, Spence BC, Gallagher JD, Wiley CW, Bertrand ML, Blike GT: Characterizing novice behavior associated with learning ultrasound-guided peripheral regional anesthesia. Reg Anesth Pain Med 2007; 32: 107-15

35. Friedman Z, Katznelson R, Devito I, Siddiqui M, Chan V: Objective assessment of manual skills and proficiency in performing epidural anesthesia--video-assisted validation. Reg Anesth Pain Med 2006; 31: 304-10

36. Naik VN, Perlas A, Chandra DB, Chung DY, Chan VW: An assessment tool for brachial plexus regional anesthesia performance: establishing construct validity and reliability. Reg Anesth Pain Med 2007; 32: 41-5 
37. Chin KJ, Tse C, Chan V, Tan JS, Lupu CM, Hayter M: Hand motion analysis using the imperial college surgical assessment device: validation of a novel and objective performance measure in ultrasound-guided peripheral nerve blockade. Reg Anesth Pain Med 2011; 36: 213-9

38. Hopkins WG: A new view of statistics. Internet Society for Sport Science: http://www.sportsci.org/resource/stats/. 2000

39. Shrout PE, Fleiss JL: Intraclass correlations: uses in assessing rater reliability. Psychol Bull 1979; 86: 420-8

40. Lexell JE, Downham DY: How to assess the reliability of measurements in rehabilitation. Am J Phys Med Rehabil 2005; 84: 719-23

41. Linn MC, Petersen AC: Emergence and characterization of sex differences in spatial ability: a meta-analysis. Child Dev 1985; 56: 1479-98

42. Kolozsvari NO, Andalib A, Kaneva P, Cao J, Vassiliou MC, Fried GM, Feldman LS: Sex is not everything: the role of gender in early performance of a fundamental laparoscopic skill. Surg Endosc 2011; 25: 1037-42

43. Grantcharov TP, Bardram L, Funch-Jensen P, Rosenberg J: Impact of hand dominance, gender, and experience with computer games on performance in virtual reality laparoscopy. Surg Endosc 2003; 17: 1082-5

44. Eysenck MW: Anxiety and cognitive-task performance. Personality and Individual Differences 1985; 6: 579-586

45. Pijpers JR, Oudejans RR, Bakker FC: Anxiety-induced changes in movement behaviour during the execution of a complex whole-body task. Q J Exp Psychol A 2005; 58: 421-45 
Table 1. Participant Demographics and Summary Statistics for Visuospatial Ability and Task Performance

Participant Demographics

Characteristics

Age in years, Mean (SD)

\section{Gender}

Male (n, \%)

Female (n, \%)

* Year of study in medical school

Year $1(\mathrm{n}, \%)$

Year $2(\mathrm{n}, \%)$

Year $3(n, \%)$

Year $4(\mathrm{n}, \%)$

Year $5(\mathrm{n}, \%)$

\section{Overall $N=60$}

$23.3(4.3)$

$30(50)$

$30(50)$

08 (14.0)

$21(36.8)$

$13(22.8)$

$11(19.3)$

$04(7.0)$

\section{Summary Statistics}

\section{$\uparrow$ Assessment}

MRT (mean, SD)

GEFT (median, IQR)

AH4 (median, IQR)

[UMACL] EA (median, IQR)

[UMACL] TA (mean, SD)

[UMACL] HT (median, IQR)

[UMACL] AF (median, IQR)

Fear of failure (mean, SD)

NRT-20 (mean, SD)

CES (median, IQR)

GRS (mean, SD)

\section{Score}

$$
\begin{aligned}
& 13.9(5.3) \\
& 17.0(14.0-17.5) \\
& 60.0(53.0-63.0) \\
& 19.0(16.5-21.5) \\
& 15.2(3.4) \\
& 27.0(25.0-29.0) \\
& 6.0(5.0-9.0) \\
& 6.8(1.6) \\
& 13.9(2.5) \\
& 6.0(3.0-10.0) \\
& 19.7(6.0)
\end{aligned}
$$

* $3(5 \%)$ missing $\uparrow$ Mean and SD (standard deviation) used for continuous variables with a normal distribution and median and IQR (Interquartile range) for continuous variables not normally distributed.

MRT - Mental Rotation Test; GEFT - The Group Embedded Figures Test; AH4 - Alice Heim Group Ability Test; [UMACL] - UWIST Mood Adjective Checklist; EA - Energetic Arousal; TA - Tense Arousal; HT Hedonic Tone; AF - Anger/Frustration; NRT-20 - Numerical Reasoning Test; CES - Composite Error Score; GRS - Global Rating Scale. 
Table 2. MRT Scores according to the Sex of the Participants

\begin{tabular}{llllll}
\hline \hline Gender & Number (\%) & MRT (Mean) & SD & 95 \% CI & P - Value \\
\hline Female & $30(50)$ & 10.9 & 4.64 & $9.16-12.63$ & \\
& & & & $<0.001$ \\
Male & $30(50)$ & 17.0 & 4.15 & $15.44-18.55$ & \\
\hline
\end{tabular}

Values are Mean and SD - Standard deviation; CI - Confidence Interval; MRT - Mental Rotation Test. 
Visuospatial, Emotional \& Numerical Reasoning Assessments

\section{Spearman's correlation coefficient ( $\rho)$} CES GRS
MRT

AH4

GEFT

$$
\begin{array}{ll}
-0.54(\mathrm{P}<0.001) & 0.47(\mathrm{P}<0.001) \\
-0.09(\mathrm{P}=0.49) & 0.09(\mathrm{P}=0.49) \\
-0.06(\mathrm{P}=0.60) & 0.00(\mathrm{P}=0.95)
\end{array}
$$

\section{UMACL}

- Energetic Arousal (EA)

- $\quad$ Tense Arousal (TA)

- Hedonic Tone (HT)

- Anger/Frustration (AF)

Fear of Failure

NRT-20

$$
\begin{array}{ll}
-0.30(\mathrm{P}=0.01) & 0.06(\mathrm{P}=0.62) \\
0.26(\mathrm{P}=0.04) & -0.35(\mathrm{P}=0.005) \\
-0.22(\mathrm{P}=0.08) & 0.18(\mathrm{P}=0.15) \\
0.16(\mathrm{P}=0.21) & -0.19(\mathrm{P}=0.13) \\
0.05(\mathrm{P}=0.69) & -0.07(\mathrm{P}=0.57) \\
0.01(\mathrm{P}=0.93) & -0.05(\mathrm{P}=0.69)
\end{array}
$$

Spearman's correlation coefficient ( $\rho$ ) of Composite Error Score (CES) and Global Rating Scale (GRS) with visuospatial, emotional and numerical reasoning assessments; Significance at $\mathrm{P}<0.05$.

MRT - Mental Rotation Test; AH4 - Alice Heim Group Ability Test; GEFT - The Group Embedded Figures Test; [UMACL] - UWIST Mood Adjective Checklist; NRT-20 Numerical Reasoning Test. 


\section{Appendix 1}

Visuo-spatial ability as a predictor of novice performance Participant in ultrasound-guided regional anaesthesia (UGRA).

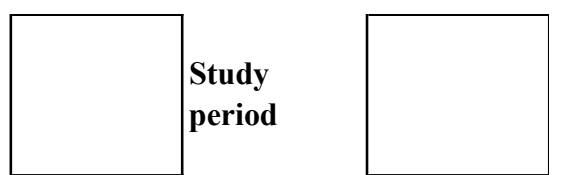

Errors - Please tick each time an error is made

Needle advanced without visualisation of needle tip

Failure to identify the target

Failure to recognise orientation of probe with the image screen

Unintentional probe movement

Target malpositioned on screen, including incorrect depth selection

Attention focussed on hand and not image as needle advanced

\section{Total number of errors}

\section{Box A}

Number of needle passes*

Box B

* A needle pass is defined as a new puncture of the turkey breast or if the needle is withdrawn towards the exterior of the turkey breast. Image quality scale (select one)

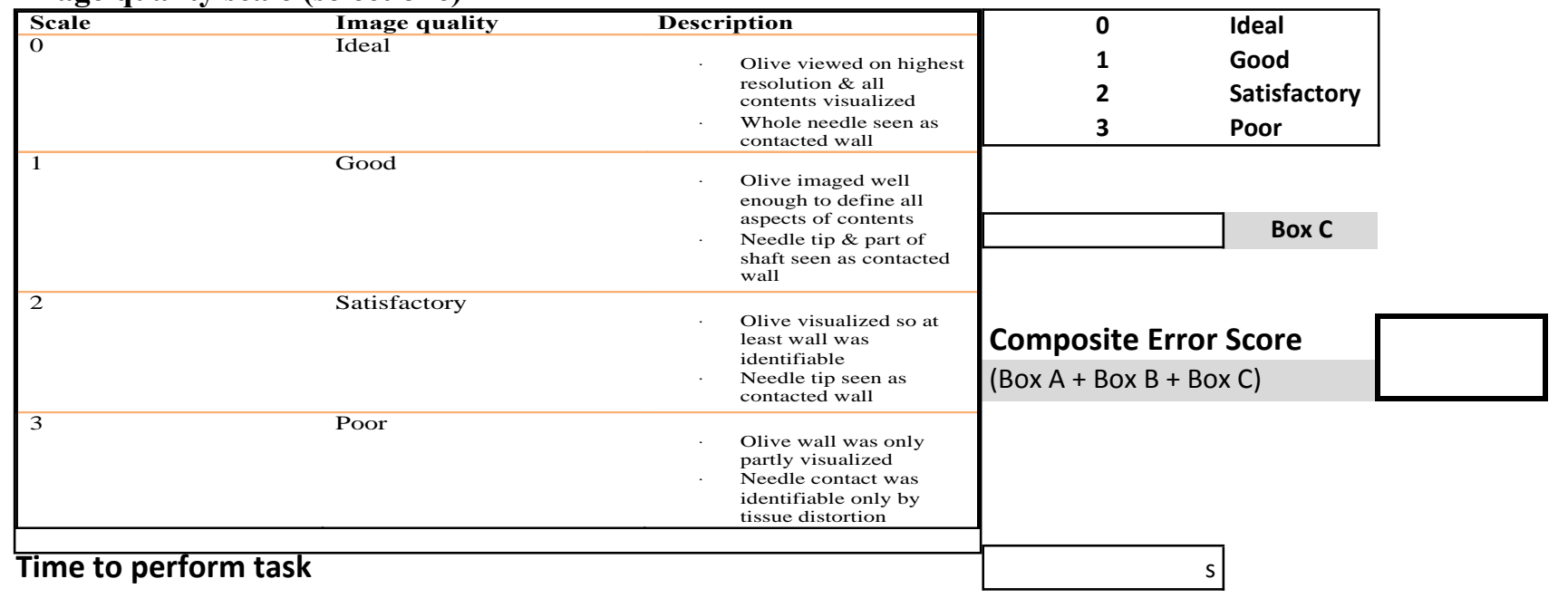




\section{Appendix 2}

\section{Visuo-spatial ability as a predictor of novice performance in ultrasound-guided regional anaesthesia (UGRA).}

\begin{tabular}{|c|c|c|c|c|c|c|c|c|c|c|}
\hline & & & & & lobal Rating & le for $\mathrm{UC}$ & & & & \\
\hline & Please tick and $s$ & ach of the ? & wap & riately; & & & & & & \\
\hline & & & & & & & & & & \\
\hline Preparation for procedure & $\begin{array}{l}\text { Did not organise } \\
\text { Has to stop proce } \\
\text { to prepare equipn }\end{array}$ & $\begin{array}{l}\text { ment well } \\
\text { requently }\end{array}$ & & & $\begin{array}{l}\text { Equipment gene } \\
\text { Occasionally ha } \\
\text { prepare items. }\end{array}$ & $\begin{array}{l}\text { organised. } \\
\text { op and }\end{array}$ & & & $\begin{array}{l}\text { All equipment neat } \\
\text { prepared and ready }\end{array}$ & $\begin{array}{l}\text { anised, } \\
\text { e. }\end{array}$ \\
\hline & [ & l & [ & l & I & l & I & l & [ & l \\
\hline Time and motion & Many unnecessar & & & & $\begin{array}{l}\text { Efficient time } / \mathrm{m} \\
\text { unnecessary mo }\end{array}$ & but some & & & $\begin{array}{l}\text { Clear economy of } n \\
\text { and maximum effic }\end{array}$ & \\
\hline & [ & ] & [ & l & I & ] & I & l & [ & l \\
\hline Instrument handling & $\begin{array}{l}\text { Repeatedly make } \\
\text { awkward moves }\end{array}$ & $\begin{array}{l}\text { tive or } \\
\text { istruments. }\end{array}$ & & & $\begin{array}{l}\text { Competent use c } \\
\text { but occasionally } \\
\text { or awkward. }\end{array}$ & $\begin{array}{l}\text { ruments } \\
\text { ared stiff }\end{array}$ & & & $\begin{array}{l}\text { Fluid moves with ir } \\
\text { and no awkwardnes }\end{array}$ & ents \\
\hline & I & l & I & l & I & l & I & l & I & l \\
\hline Flow of Procedure & $\begin{array}{l}\text { Frequently stoppe } \\
\text { and seemed unsur }\end{array}$ & $\begin{array}{l}\text { cedure } \\
\text { lext move. }\end{array}$ & & & $\begin{array}{l}\text { Demonstrated sc } \\
\text { planning with re } \\
\text { progression of } p\end{array}$ & $\begin{array}{l}\text { orward } \\
\text { ble } \\
\text { ure. }\end{array}$ & & & $\begin{array}{l}\text { Obviously planned } \\
\text { procedure with effo } \\
\text { from one move to th }\end{array}$ & $\begin{array}{l}\text { e of } \\
\text { flow } \\
\text { t. }\end{array}$ \\
\hline & I & l & I & l & I & l & I & l & I & l \\
\hline Image quality & $\begin{array}{l}\text { Inadequate image } \\
\text { visualised. Needl } \\
\text { identifiable by tis }\end{array}$ & $\begin{array}{l}\text { et partially } \\
\text { ement only } \\
\text { stortion. }\end{array}$ & & & $\begin{array}{l}\text { Good image. Mc } \\
\text { visualised. Need } \\
\text { needle shaft visi }\end{array}$ & $\begin{array}{l}\text { target } \\
\text { and part of }\end{array}$ & & & $\begin{array}{l}\text { Outstanding image. } \\
\text { image with comple } \\
\text { visualised. Whole o }\end{array}$ & $\begin{array}{l}\text { uivocal } \\
\text { cture } \\
\text { dle visible. }\end{array}$ \\
\hline & [ & ] & [ & l & [ & l & I & l & [ & l \\
\hline Knowledge of procedure & Deficient knowle & & & & $\begin{array}{l}\text { Knew all import } \\
\text { procedure }\end{array}$ & eps of & & & $\begin{array}{l}\text { Demonstrated fami } \\
\text { aspects of procedur }\end{array}$ & with all \\
\hline & I & l & [ & l & [ & l & I & l & [ & l \\
\hline Overall performance & Very poor. & l & [ & l & Competent. & l & [ & l & $\begin{array}{r}\text { Clearly superior. } \\
\text { [ }\end{array}$ & l \\
\hline
\end{tabular}

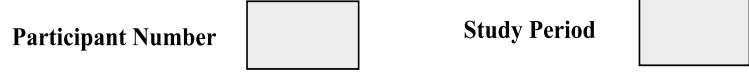

lobal Rating Scale for UGRA 


\section{Medical Students}

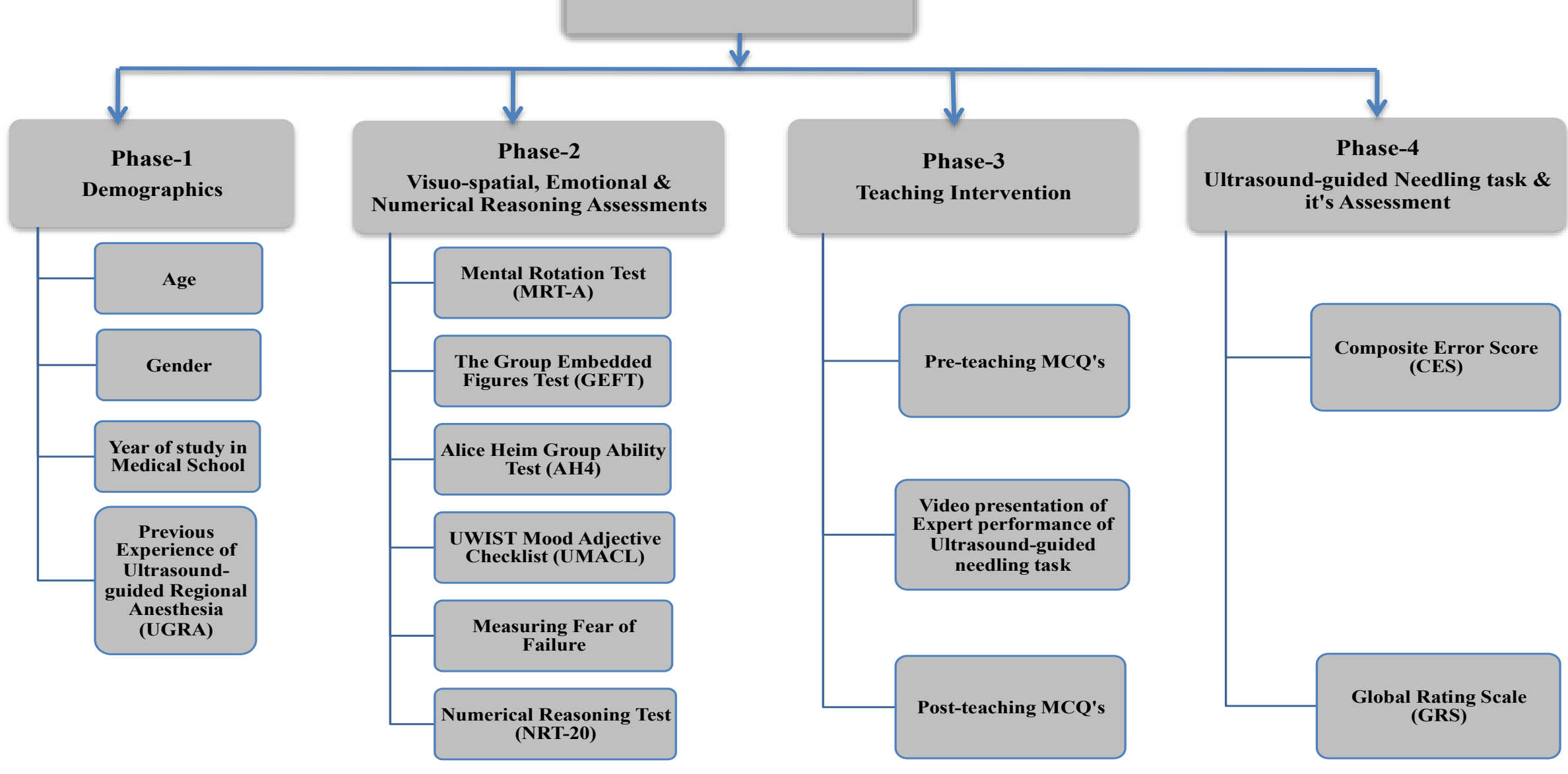

Figure 1. Flowchart showing Study Design 


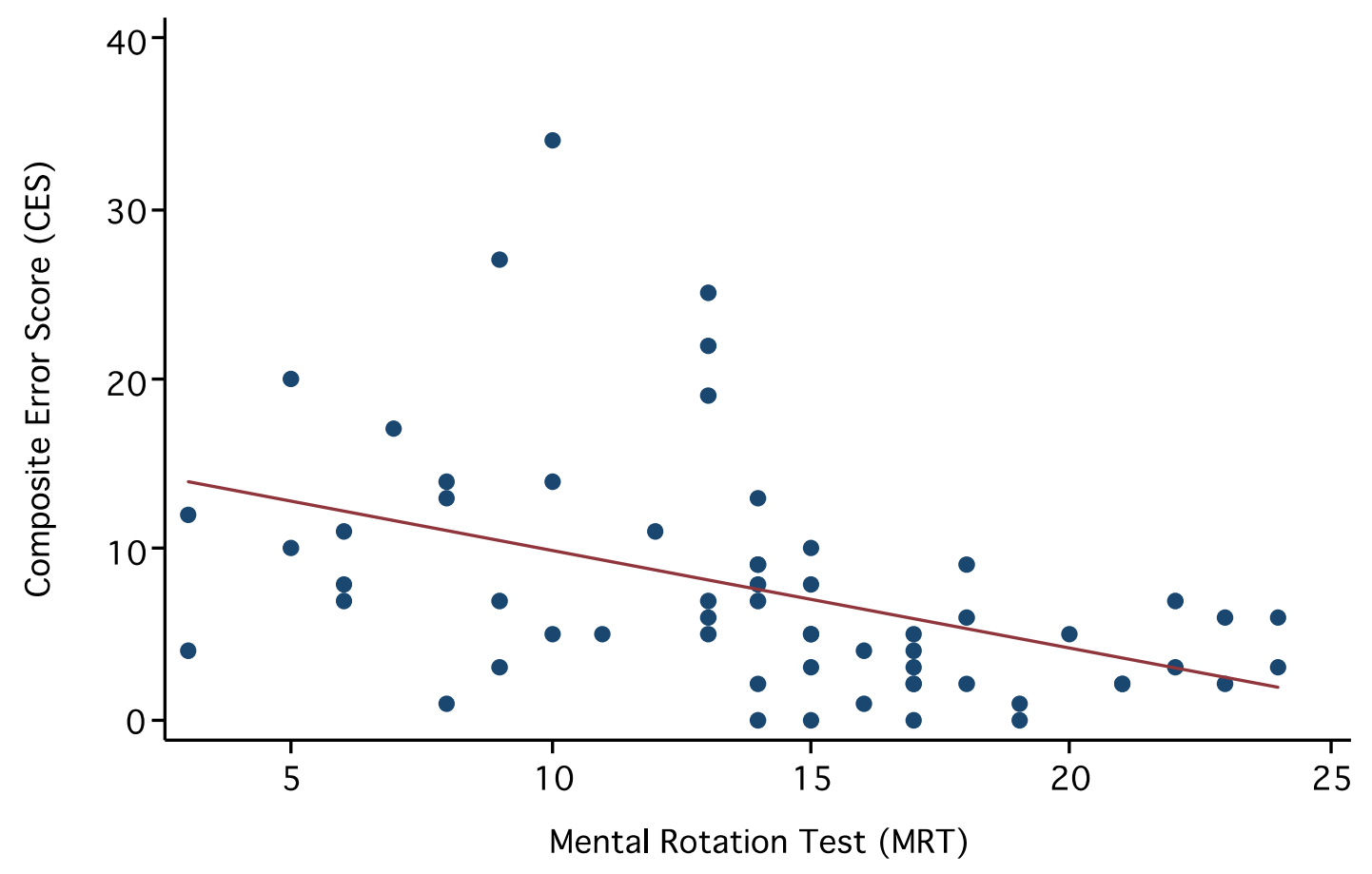

Figure 2. Relationship of CES with MRT.

MRT is negatively correlated with CES, which reveals that increasing error rate is associated with low MRT scores. 


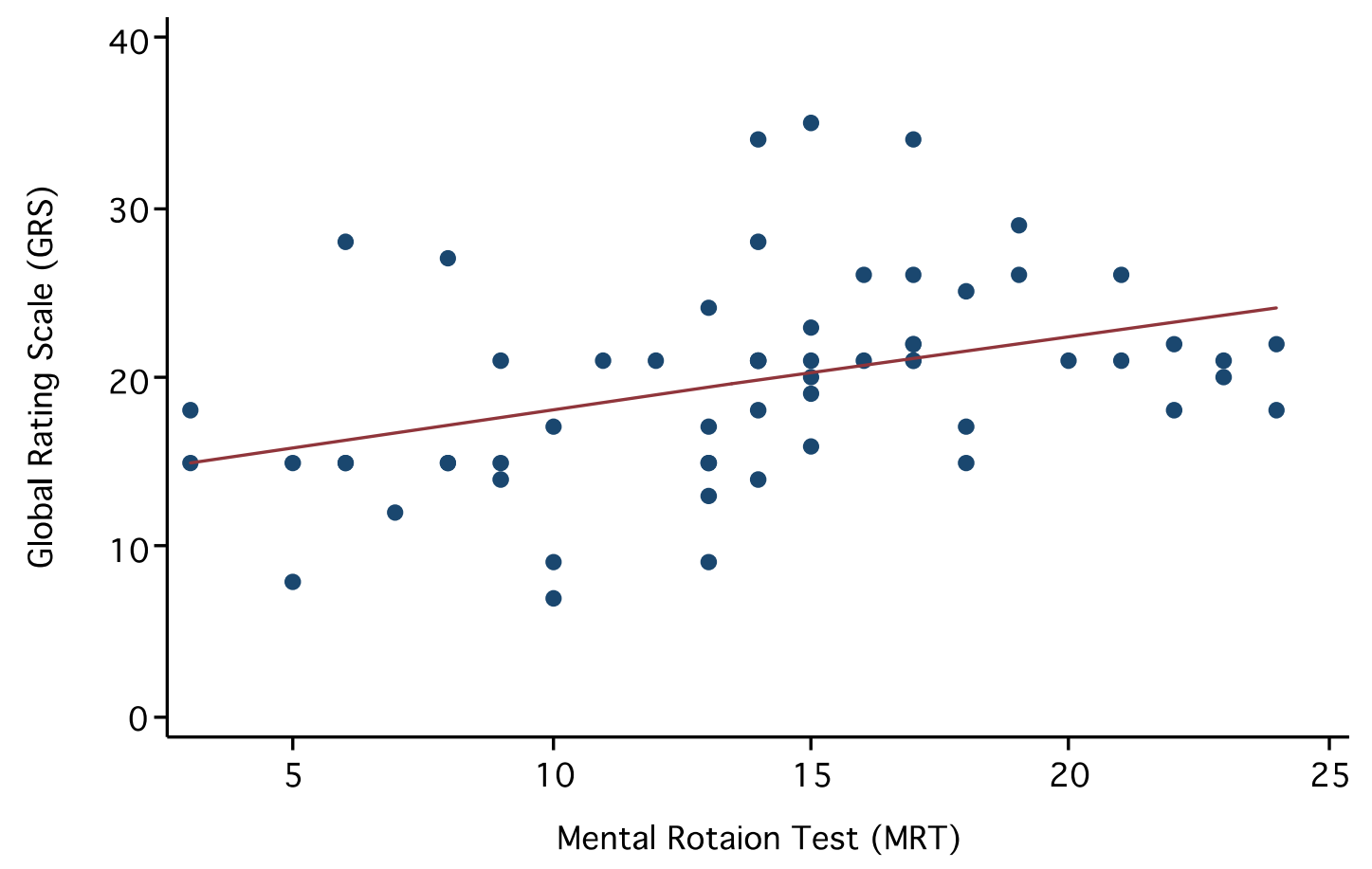

Figure 3. Relationship of GRS with MRT.

MRT is positively correlated with GRS, which shows that enhanced GRS quality scores are associated with high MRT scores. 